\title{
EDITORIAL
}

\section{Activity limitation: a major consequence of dyspnoea in COPD}

\section{N. Roche}

$\mathrm{n}$ the present issue of the European Respiratory Review, Jolley and MoxhaM [1] present "A physiological model of patient-reported breathlessness during daily activities in COPD [chronic obstructive pulmonary disease]". The purpose of their interesting approach is to explain why a given patient may experience breathlessness in some particular situations of his/her daily life, based on the various possible mechanisms of dyspnoea in COPD. This understanding may obviously help in building individualised relieving strategies through counselling and education, occupational therapy, pharmacological agents and physical training.

The ultimate goal of targeting dyspnoea is to improve health status and survival by allowing the patient to increase his/her daily activity. Therefore, to implement the appropriate strategies, the clinician first needs to apprehend the extent to which, and the reasons why, a patient limits this activity. The purpose of this editorial is to increase the awareness of this important aspect of COPD care and to provide clinicians with a few key points for discussion.

\section{ACTIVITY LIMITATION IN COPD: ITS DETERMINANTS AND MEASUREMENT}

Activity limitation has both quantitative and qualitative aspects: on the one hand, it refers to the reduction in the daily amount (i.e. intensity, frequency and duration) of activity; on the other hand, it covers the discomfort induced by activities that are still performed in a normal or near-normal amount. Many studies have found a marked reduction in the level of daily physical activity in patients with COPD, including those with moderately to mildy impaired lung function, compared with control populations with similar sociodemographic characteristics (fig. 1) [3-5]. Factors independently associated with the level of daily physical activity include sociodemographic characteristics (activity is decreased in females, older patients and those with a higher socioeconomic status), comorbidity, quality of life, disease severity and the use of long-term oxygen therapy $[4,6]$.

A major contributor to the level of daily activity is obviously exercise tolerance [5]. In terms of symptoms, determinants of activity and exercise tolerance are not limited to dyspnoea: they also include leg discomfort and less specific complaints, such as fatigue [7]. In a way similar to the more global concept of quality of life, fatigue is not a unidimensional manifestation of disease but relates to several domains that can be classified as general, physical, mental and cognitive. Among them, exercise tolerance correlates rather well with the general and physical domains.

The level of a given activity does not relate only to exercise tolerance: other factors are involved, such as the necessity or desirability of that activity [8]. Dyspnoea can induce an increased discomfort during a given activity without preventing it being performed, if the patient feels it is worth making a greater effort to achieve it. In that sense, "quality of life-like" (or, more simply, qualitative) items may be more sensitive than quantitative activity measurement at assessing the consequences of the impairment in exercise performance, since it will capture both restrictions and increased symptomatic cost [9].

Daily activity can be estimated by questionnaires [10] or more objective instruments, i.e. motion sensors such as pedometers or accelerometers [11]. Studies have shown some differences between the results obtained using these methods of measurement $[2,12]$. Such variations may be the consequence of an irregular use of the motion sensor or errors when filling daily diaries. However, they are also likely to relate to the multiple components of activity mentioned above (quantitative, qualitative, symptom/exercise tolerance-limited or linked to other factors); in other words, the two categories of tools do not capture the same aspect of daily activity, with one focusing on perceived activity and the sense of effort/gratification that it provides, the other being restricted to physical movement. This explains the discrepancy.

\section{CORRELATES OF DYSPNOEA AND ACTIVITY LIMITATION: FROM QUALITY OF LIFE TO SURVIVAL}

Activity limitation obviously impairs quality of life by restricting the patient's interactions with
CORRESPONDENCE

N. Roche

Service de Pneumologie et

Réanimation

Hôpital de l'Hôtel Dieu

1 place du Parvis de Notre-Dame 75004 Paris

France

E-mail: nicolas.roche@htd.aphp.fr

Received:

March 062009

Accepted:

March 062009

STATEMENT OF INTEREST

In the past 5 years, N. Roche received fees for speaking, organising education or consulting from Altana Pharma, AstraZeneca, Boehringer Ingelheim, Chiesi, GlaxoSmithKline and Pfizer.

PROVENANCE

Submitted article, peer reviewed 


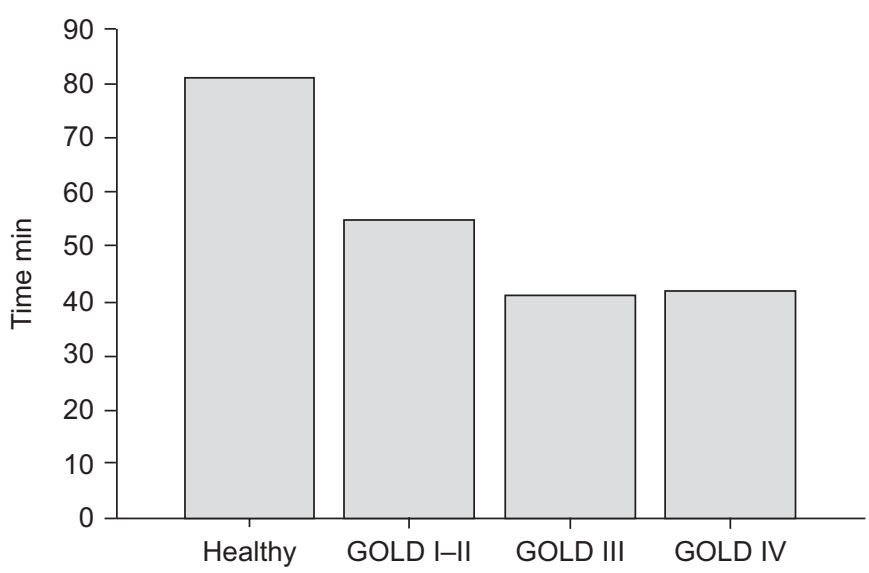

FIGURE 1. Mean daily time spent walking by Global Initiative for Obstructive Lung Disease (GOLD) stage in chronic obstructive pulmonary disease compared with healthy subjects. Data taken from [2].

his/her environment. In addition, it makes it difficult for the patient to preserve his/her sense of integrity, which is closely related to both the sense of effectiveness (being able to) and the sense of connectedness (being with) [13]. Besides, dyspnoea and exercise performance are related to another determinant of quality of life, i.e. self-esteem [14]. Finally, dyspnoea and the limitation in activity that it induces may be such distressing that they lead to anxiety and depression, which are frequently observed in COPD [15].

Exercise tolerance measured using field or laboratory tests has been shown to explain some of the variations in quality of life [16-18]. However, activity limitation per se may also account for up to $52 \%$ of the variance in quality of life, as measured using specific questionnaires in patients with chronic respiratory failure [19]. In some studies, in which both dyspnoea and exercise performance (estimated by the 6-min walk distance) were studied as determinants of quality of life, dyspnoea during daily activity (assessed by the baseline and transition dyspnoea index) appeared to be the most important contributor [20]. Among quality of life domains, those related to activity limitation are the most closely linked to lung function [21].

Beyond its influence on quality of life, a low level of daily activity is associated with an increased risk of hospital admission for acute exacerbations of COPD and mortality, as shown by the Copenhagen City Heart Survey: in that study, the level of activity was assessed by questionnaires at entry and the follow-up lasted up to 20 yrs (fig. 2) [22, 23]. In another study in Spain, self-reported activity was an independent prognostic factor, together with airflow obstruction, general health condition and dyspnoea [24]. Other studies have also found significant associations between leisure time physical activity and all-cause, cardiovascular and noncardiovascular mortality $[25,26]$.

Such results are not that surprising since daily activity is correlated with exercise performance, a known predictor of survival in COPD patients, whether assessed by field tests (such as the 6-min walk test) or maximal laboratory tests (maximal oxygen uptake) [27]. Likewise, so is physical fitness, as reflected, for example, by muscle strength [28].

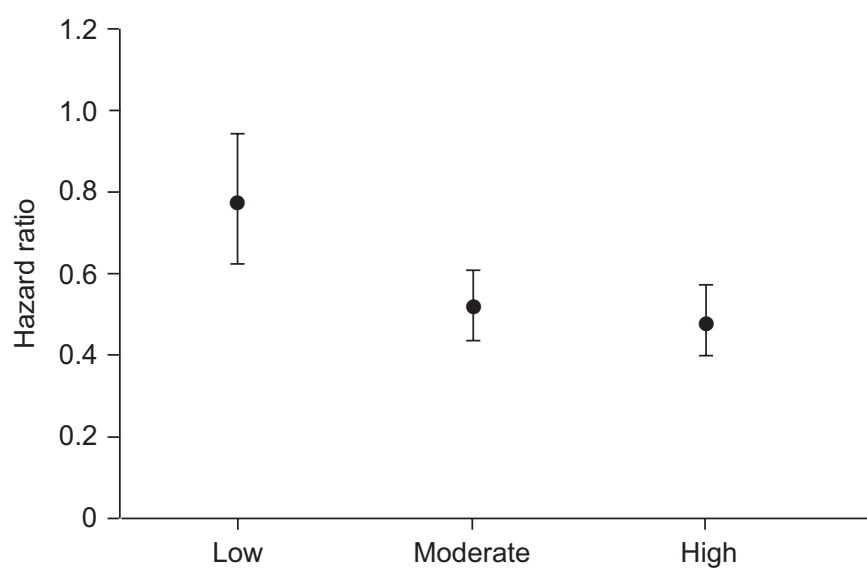

FIGURE 2. Hazard ratio of death from all causes during follow-up in the Copenhagen City Heart Study, stratified by level of physical activity at entry. The reference is the group with very low physical activity. Levels of activity are defined as follows. Low: engaging in light physical activity, such as walking or biking for $<2 \mathrm{~h}$ per week; moderate: engaging in light physical activity for 2-4 h per week; high: engaging in light physical activity for $>4 \mathrm{~h}$ per week or in more vigorous activity for any duration. Bars represent 95\% confidence intervals. Data taken from [22].

Altogether, daily activity relates to both quality of life and mortality. It is also associated with exercise performance. Interestingly, all these correlates of activity are quite closely linked together: the BODE index (body mass index, airflow obstruction, dyspnoea and exercise capacity index), which integrates dyspnoea and the 6-min walking distance, is both a predictor of mortality and a correlate of quality of life [29, 30].

\section{INCREASING ACTIVITY IN COPD: A NECESSARY COOPERATION}

As outlined earlier, increasing daily activity of COPD patients has the potential for improving both quality of life and survival. Indeed, the increase in daily walking distance after rehabilitation parallels that of 6-min walk distance on the one hand and quality of life on the other [31, 32]. In addition, the improvement in exercise tolerance provided by exercise training correlates to nearly all (i.e. not only the physical) domains of quality of life [33].

Both pharmacological and nonpharmacological (rehabilitation) approaches have the potential to improve activity and can provide complementary effects on exercise performance: for instance, both bronchodilators and oxygen therapy may increase the level and the efficacy of exercise training by decreasing hyperinflation [34, 35]. In a given patient, the respective effects of bronchodilators and exercise training depend, in part, on the locus of symptom limitation, i.e. leg fatigue or dyspnoea [36].

In itself, exercise counselling with feedback using, for example, pedometers, has some efficacy for increasing daily activity and physical fitness [37, 38]. In the context of pulmonary rehabilitation, activity-specific training (including supervised physical activity) may provide additional benefits to "simple" exercise training [39]. Similarly, including recreational activities in the training programme may enhance the efficacy of rehabilitation [40]. Importantly, the effect of rehabilitation on daily activity appears to increase with the duration of 
programmes, as shown for both movement intensity and daily walking time [41].

In any case, maintenance is highly important in preserving the benefits obtained after a course of pulmonary rehabilitation. Indeed, participation at regular walking courses after completion of the initial programme is associated with a slower decline in quality of life and walking self-efficacy and less progression of dyspnoea during daily activities [42]. Rollators (wheeled walking frames) may help increasing and maintaining daily activity, thereby improving well-being, as demonstrated by the high proportion of patients (up to 50\%) who continue to use them daily, even outdoors [43].

Other strategies to improve activity obviously depend on the mechanisms of its limitation. In that sense, the approach proposed by MOXHAM and JOLLEY [1] is of major interest. For instance, in some patients, physiotherapy approaches such as pursed-lips breathing may be of help by reducing exertional dyspnoea and improving physical function [44]. Ambulatory oxygen therapy, which aims to increase activity and make it easier, does not necessarily improve quality of life, since it is also associated with significant constraints and side-effects, such as decreased self-esteem. However, benefits may appear slowly as the patient gets use to this treatment [45].

\section{CONCLUSION}

Activity limitation is a hallmark of COPD. It is the consequence of dyspnoea and poor exercise functional capacity, and is involved in quality of life impairment and increased mortality. Therefore, improving the level of daily activity is a major goal in the care of COPD patients. It implies improving exercise tolerance, at least in a great part through the reduction in the level of dyspnoea that is perceived in the various exercising situations of daily life. Therefore, understanding the corresponding mechanisms of dyspnoea is of utmost importance. The readers will be greatly helped to reach this objective by the paper by Jolley and Moxham [1] in this issue of the Review.

\section{REFERENCES}

1 Jolley CJ, Moxham J. A physiological model of patientreported breathlessness during daily activities in COPD. Eur Respir Rev 2009; 18: 66-79.

2 Pitta F, Troosters T, Spruit MA, et al. Activity monitoring for assessment of physical activities in daily life in patients with chronic obstructive pulmonary disease. Arch Phys Med Rehabil 2005; 86: 1979-1985.

3 Sandland CJ, Singh SJ, Curcio A, et al. A profile of daily activity in chronic obstructive pulmonary disease. J Cardiopulm Rehabil 2005; 25: 181-183.

4 Garcia-Aymerich J, Felez MA, Escarrabill J, et al. Physical activity and its determinants in severe chronic obstructive pulmonary disease. Med Sci Sports Exerc 2004; 36: 16671673.

5 Pitta F, Troosters T, Spruit MA, et al. Characteristics of physical activities in daily life in chronic obstructive pulmonary disease. Am J Respir Crit Care Med 2005; 171: 972-977.

6 Eisner MD, Trupin L, Katz PP, et al. Development and validation of a survey-based COPD severity score. Chest 2005; 127: 1890-1897.
7 Breslin E, van der Schans C, Breukink S, et al. Perception of fatigue and quality of life in patients with COPD. Chest 1998; 114: 958-964.

8 Reardon JZ, Lareau SC, ZuWallack R. Functional status and quality of life in chronic obstructive pulmonary disease. Am J Med 2006; 119: 32-37.

9 Jones PW. Activity limitation and quality of life in COPD. COPD 2007; 4: 273-278.

10 Nield M, Hoo GS, Roper J, et al. Usefulness of the human activity profile, a functional performance measure, in people with chronic obstructive pulmonary disease. J Cardiopulm Rehabil 2005; 25: 115-121.

11 Steele BG, Belza B, Cain $\mathrm{K}$, et al. Bodies in motion: monitoring daily activity and exercise with motion sensors in people with chronic pulmonary disease. J Rehabil Res Dev 2003; 40: 45-58.

12 Moore R, Berlowitz D, Denehy L, et al. Comparison of pedometer and activity diary for measurement of physical activity in chronic obstructive pulmonary disease. J Cardiopulm Rehabil Prev 2009; 29: 57-61.

13 Leidy NK, Haase JE. Functional status from the patient's perspective: the challenge of preserving personal integrity. Res Nurs Health 1999; 22: 67-77.

14 Ninot G, Moullec G, Desplan J, et al. Daily functioning of dyspnea, self-esteem and physical self in patients with moderate COPD before, during and after a first inpatient rehabilitation program. Disabil Rehabil 2007; 29: 1671-1678.

15 ZuWallack R. How are you doing? What are you doing? Differing perspectives in the assessment of individuals with COPD. COPD 2007; 4: 293-297.

16 Ozalevli S, Ozden A, Itil O, et al. Comparison of the sit-tostand test with 6 min walk test in patients with chronic obstructive pulmonary disease. Respir Med 2007; 101: 286-293.

17 Wadell K, Sundelin G, Henriksson-Larsen K, et al. High intensity physical group training in water-an effective training modality for patients with COPD. Respir Med 2004; 98: 428-438.

18 Laviolette L, Bourbeau J, Bernard S, et al. Assessing the impact of pulmonary rehabilitation on functional status in COPD. Thorax 2008; 63: 115-121.

19 Duiverman ML, Wempe JB, Bladder G, et al. Health-related quality of life in COPD patients with chronic respiratory failure. Eur Respir J 2008; 32: 379-386.

20 von Leupoldt A, Hahn E, Taube K, et al. Effects of 3-week outpatient pulmonary rehabilitation on exercise capacity, dyspnea, and quality of life in COPD. Lung 2008; 186: 387-391.

21 Liang WM, Chen JJ, Chang $\mathrm{CH}$, et al. An empirical comparison of the WHOQOL-BREF and the SGRQ among patients with COPD. Qual Life Res 2008; 17: 793-800.

22 Garcia-Aymerich J, Lange P, Benet M, et al. Regular physical activity reduces hospital admission and mortality in chronic obstructive pulmonary disease: a population based cohort study. Thorax 2006; 61: 772-778.

23 Bahadori K, FitzGerald JM. Risk factors of hospitalization and readmission of patients with COPD exacerbation-systematic review. Int J Chron Obstruct Pulmon Dis 2007; 2: 241-251.

24 Esteban C, Quintana JM, Aburto M, et al. A simple score for assessing stable chronic obstructive pulmonary disease. QJM 2006; 99: 751-759. 
25 Reilly KH, Gu D, Duan X, et al. Risk factors for chronic obstructive pulmonary disease mortality in Chinese adults. Am J Epidemiol 2008; 167: 998-1004.

26 Batty GD, Shipley MJ, Marmot MG, et al. Leisure time physical activity and disease-specific mortality among men with chronic bronchitis: evidence from the Whitehall study. Am J Public Health 2003; 93: 817-821.

27 Cote CG, Pinto-Plata V, Kasprzyk K, et al. The 6-min walk distance, peak oxygen uptake, and mortality in COPD. Chest 2007; 132: 1778-1785.

28 Buchman AS, Boyle PA, Wilson RS, et al. Pulmonary function, muscle strength and mortality in old age. Mech Ageing Dev 2008; 129: 625-631.

29 Ong KC, Lu SJ, Soh CS. Does the multidimensional grading system (BODE) correspond to differences in health status of patients with COPD? Int J Chron Obstruct Pulmon Dis 2006; 1: 91-96.

30 Medinas-Amoros M, Alorda C, Renom F, et al. Quality of life in patients with chronic obstructive pulmonary disease: the predictive validity of the BODE index. Chron Respir Dis 2008; 5: 7-11.

31 Belza B, Steele BG, Hunziker J, et al. Correlates of physical activity in chronic obstructive pulmonary disease. Nurs Res 2001; 50: 195-202.

32 Behnke M, Taube C, Kirsten D, et al. Home-based exercise is capable of preserving hospital-based improvements in severe chronic obstructive pulmonary disease. Respir Med 2000; 94: 1184-1191.

33 Benzo R, Flume PA, Turner D, et al. Effect of pulmonary rehabilitation on quality of life in patients with COPD: the use of SF-36 summary scores as outcomes measures. J Cardiopulm Rehabil 2000; 20: 231-234.

34 Zuwallack RL. The roles of bronchodilators, supplemental oxygen, and ventilatory assistance in the pulmonary rehabilitation of patients with chronic obstructive pulmonary disease. Respir Care 2008; 53: 1190-1195.

35 Casaburi R, Kukafka D, Cooper CB, et al. Improvement in exercise tolerance with the combination of tiotropium and pulmonary rehabilitation in patients with COPD. Chest 2005; 127: 809-817.
36 Deschenes D, Pepin V, Saey D, et al. Locus of symptom limitation and exercise response to bronchodilation in chronic obstructive pulmonary disease. I Cardiopulm Rehabil Prev 2008; 28: 208-214.

37 Hospes G, Bossenbroek L, ten Hacken NH, et al. Enhancement of daily physical activity increases physical fitness of outclinic COPD patients: results of an exercise counseling program. Patient Educ Couns 2008; [Epub ahead of print PMID: 19036552].

38 de Blok BM, de Greef $\mathrm{MH}$, ten Hacken $\mathrm{NH}$, et al. The effects of a lifestyle physical activity counseling program with feedback of a pedometer during pulmonary rehabilitation in patients with COPD: a pilot study. Patient Educ Couns 2006; 61: 48-55.

39 Norweg AM, Whiteson J, Malgady R, et al. The effectiveness of different combinations of pulmonary rehabilitation program components: a randomized controlled trial. Chest 2005; 128: 663-672.

40 Nakamura Y, Tanaka K, Shigematsu R, et al. Effects of aerobic training and recreational activities in patients with chronic obstructive pulmonary disease. Int $J$ Rehabil Res 2008; 31: 275-283.

41 Pitta F, Troosters T, Probst VS, et al. Are patients with COPD more active after pulmonary rehabilitation? Chest 2008; 134: 273-280.

42 Heppner PS, Morgan C, Kaplan RM, et al. Regular walking and long-term maintenance of outcomes after pulmonary rehabilitation. J Cardiopulm Rehabil 2006; 26: 44-53.

43 Hill K, Goldstein R, Gartner EJ, et al. Daily utility and satisfaction with rollators among persons with chronic obstructive pulmonary disease. Arch Phys Med Rehabil 2008; 89: 1108-1113

44 Nield MA, Soo Hoo GW, Roper JM, et al. Efficacy of pursed-lips breathing: a breathing pattern retraining strategy for dyspnea reduction. J Cardiopulm Rehabil Prev 2007; 27: 237-44.

45 Sandland CJ, Morgan MD, Singh SJ. Patterns of domestic activity and ambulatory oxygen usage in COPD. Chest 2008; 134: 753-760. 